\title{
Perifosine-mediated Akt inhibition in neuroendocrine tumor cells: role of specific Akt isoforms
}

\author{
Kathrin Zitzmann ${ }^{1}$, George Vlotides ${ }^{1}$, Stephan Brand ${ }^{1}$, Harald Lahm ${ }^{2, \dagger}$, \\ Gerald Spöttl ${ }^{1}$, Burkhard Göke ${ }^{1}$ and Christoph J Auernhammer ${ }^{1}$
}

\author{
${ }^{1}$ Department of Internal Medicine II, University-Hospital Munich-Grosshadern, Munich, Germany \\ ${ }^{2}$ Institute of Molecular Animal Breeding and Biotechnology, Gene Center, Ludwig-Maximilians University, Munich, Germany \\ (Correspondence should be addressed to C J Auernhammer; Email: christoph.auernhammer@med.uni-muenchen.de) \\ ${ }^{\dagger}(\mathrm{H}$ Lahm is now at Department of Cardiovascular Surgery, German Heart Center, Technical University, Munich, Germany)
}

\begin{abstract}
The majority of neuroendocrine tumors (NETs) of the gastroenteropancreatic system show aberrant Akt activity. Several inhibitors of the phosphoinositide 3-kinase (PI(3)K)-Akt-mTOR signaling pathway are currently being evaluated in clinical phase II and III studies for the treatment of NETs with promising results. However, the molecular mechanisms and particularly the role of different Akt isoforms in NET signaling are not fully understood. In this study, we examine the effect of Akt inhibition on NET cells of heterogeneous origin. We show that the Akt inhibitor perifosine effectively inhibits Akt phosphorylation and cell viability in human pancreatic (BON1), bronchus (NCl-H727), and midgut (GOT1) NET cells. Perifosine treatment suppressed the phosphorylation of Akt downstream targets such as GSK3 $\alpha / \beta, M D M 2$, and p70S6K and induced apoptosis. To further investigate the role of individual Akt isoforms for NET cell function, we specifically blocked Akt1, Akt2, and Akt3 via siRNA transfection. In contrast to Akt2 knockdown, knockdown of Akt isoforms 1 and 3 decreased phosphorylation levels of GSK3 $\alpha / \beta$, MDM2, and p70S6K and suppressed NET cell viability and colony-forming capacity. The inhibitory effect of simultaneous downregulation of Akt1 and Akt3 on tumor cell viability was significantly stronger than that caused by downregulation of all Akt isoforms, suggesting a particular role for Akt1 and Akt3 in NET signaling. Akt3 siRNA-induced apoptosis while all three isoform-specific siRNAs impaired BON1 cell invasion. Together, our data demonstrate potent antitumor effects of the panAkt inhibitor perifosine on NET cells in vitro and suggest that selective targeting of Akt1 and/or Akt3 might improve the therapeutic potential of Akt inhibition in NET disease.
\end{abstract}

Endocrine-Related Cancer (2012) 19 423-434

\section{Introduction}

Constitutive activation of the phosphoinositide 3-kinase (PI(3)K)-Akt-mTOR pathway is a common mechanism, by which tumor cells promote proliferation and cell survival. Estimates suggest that activating mutations in one or another $\mathrm{PI}(3) \mathrm{K}-\mathrm{Akt}-\mathrm{mTOR}$ pathway component account for up to $30 \%$ of all human cancers and this has been associated with poor prognosis (Luo et al. 2003, Sawyers 2006). Lost expression of the PI(3)K inhibitor PTEN and aberrant activity of Akt and mTOR have been observed in different neuroendocrine tumors (NETs) of heterogeneous origin (Wang et al. 2002, Shah et al. 2006, Kasajima et al. 2011). Akt is the primary effector of $\mathrm{PI}(3) \mathrm{K}$-generated phosphatidylinositol $(3,4,5)$-trisphosphate, thus being a principle mediator of growth factor-induced signal transduction. Through coordinated phosphorylation of downstream targets, Akt impinges on numerous cellular processes including proliferation, metabolism, survival, and migration. 
Recent pharmaceutical efforts have resulted in the development of drugs targeting the PI(3)K-AktmTOR pathway. In two large placebo-controlled clinical phase III studies, the mTOR inhibitor everolimus has improved progression-free survival in patients with NETs of the pancreas as well as in patients with NETs of different origin suffering from carcinoid syndrome (Pavel et al. 2011, Yao et al. 2011). Perifosine is an oral alkylphospholipid, which interferes with the recruitment of Akt to the plasma membrane and inhibits the phosphorylation of Akt and multiple of its downstream targets including MDM2, GSK3 $\alpha / \beta$, and p70S6K (Momota et al. 2005, Rahmani et al. 2005, Hideshima et al. 2006). Perifosine causes growth inhibition in various tumor cell lines and was also shown to sensitize tumor cells to conventional therapeutic antitumor agents and radiation (Momota et al. 2005, Rahmani et al. 2005, Vink et al. 2006). As mTOR inhibition may result in the activation of upstream PI(3)K/Akt neuroendocrine signaling (Zitzmann et al. 2010), direct Akt inhibition with perifosine could suppress this compensatory mechanism.

In mammals, Akt exists in three closely related isoforms with distinct expression patterns. While Akt1 is ubiquitously expressed, Akt2 expression varies between different organs, with high expression levels in insulin-responsive tissues such as muscle and liver. In contrast, Akt3 expression is more restricted to neuronal tissue (Stambolic \& Woodgett 2006, Mendoza \& Blenis 2007). Although redundant functions between the isoforms exist, recent investigations have demonstrated unique cell-type specific functions for each. Mice lacking Akt1 have small body size, mice lacking Akt2 show a diabetic phenotype, and mice lacking Akt3 have reduced brain size (Cho et al. 2001a,b, Easton et al. 2005, Tschopp et al. 2005). In melanoma cells, Akt3 was found to be the principal Akt isoform involved in tumor development, while in malignant glioma, Akt2 was shown to promote cell migration, invasion, and viability (Stahl et al. 2004, Zhang et al. 2009, Mure et al. 2010). In breast cancer, Akt1, though playing an important role in tumor induction, inhibits metastasis while Akt 2 exhibits promigratory effects and facilitates proliferation and cell survival (Hutchinson et al. 2004, Dillon et al. 2009). Furthermore, in thyroid cancer and non-small cell lung cancer, tumor progression is predominantly regulated by Akt1 (Lee et al. 2011, Saji et al. 2011).

Here, we report inhibitory effects of the Akt inhibitor perifosine and isoform-specific siRNA against Akt1 and Akt3 on NET cell activity.

\section{Materials and methods}

\section{Cell culture and stable transfection}

Human pancreatic neuroendocrine BON1 tumor cells were kindly provided by R Göke (Marburg, Germany) and were cultured in DMEM/F12 (1:1) medium (Gibco/Invitrogen). Stable BON1 clones were established as described previously (Vlotides et al. 2004). Human insulinoma CM cells and human midgut carcinoid GOT1 cells were kindly provided by $\mathrm{P}$ Pozzilli (Rome, Italy) and Ola Nilsson (Göteborg, Sweden) respectively. Human bronchopulmonary neuroendocrine NCI-H727 tumor cells were purchased from ATCC (Manassas, VA, USA). CM, GOT1, and NCI-H727 cells were cultured in RPMI-1640 medium (PAA, Pasching, Austria). All media were supplemented with $10 \%$ FCS (Biochrom, Berlin, Germany), $1 \%$ penicillin/streptomycin (Gibco), and $0.4 \%$ amphotericin B (Biochrom). GOT1 culture medium was additionally supplemented with $0.135 \mathrm{IU} / \mathrm{ml}$ insulin (B Braun, Melsungen, Germany) and $5 \mu \mathrm{g} / \mathrm{ml}$ apotransferrin (Sigma-Aldrich). All cells were cultured at $37^{\circ} \mathrm{C}$ in a $5 \% \mathrm{CO}_{2}$ atmosphere.

\section{Reagents}

Perifosine was kindly provided by Aeterna Zentaris (Frankfurt, Germany).

\section{Transfection of siRNA}

All siRNA oligonucleotides, including the nontargeting siRNA, were purchased from Ambion, Inc. (Austin, TX, USA). The siRNA sequences used in this study are as follows: 5'-UUAUGCCGAUCGCGUCACAUU-3' (B-GAL); 5'-GGGCACUUUCGGCAAGGUGtt-3' (Akt1); 5'-GGAUGAAGUCGCUCACACAtt- $3^{\prime}$ (Akt2); and 5'-GGACCGCACACGUUUCUAUtt- $3^{\prime}$ (Akt3). Cells were transfected in antibiotic- and FCS-free medium using DharmaFECT 2 (BON1 and CM) and Dharmafect 3 (NCI-H727) according to the manufacturer's instructions (Dharmacon, Lafayette, CO, USA). Twenty-four hours after transfection, FCS was added in a final concentration of $10 \%$.

\section{Assessment of cell viability}

Metabolic activity was measured using Cell Titer 96 $\mathrm{Aq}_{\text {ueous }}$ One Solution Cell Proliferation Assay (Promega) according to the manufacturer's instructions. Following 3 h of incubation with Cell Titer 96 solution, absorbance at $492 \mathrm{~nm}$ was determined using an ELISA plate reader. 


\section{Colony-forming assay}

Anchorage-independent growth was examined in a methylcellulose-based clonogenic assay. Cells were trypsinized and resuspended in DMEM/Ham's-F12 medium containing $0.9 \%$ methylcellulose (Fluka, Deisenhofen, Germany) and 10\% FCS. Aliquots of $1 \mathrm{ml}$ containing 500 cells were plated into $35 \mathrm{~mm}$ bacteriological Petri dishes (Greiner, Nürtingen, Germany) in the presence of insulin-like growth factor $1(100 \mathrm{ng} / \mathrm{ml})$. Developing colonies containing more than 50 cells were counted under an inverted microscope after 14-16 days.

\section{Invasion assay}

Invasion of the tumor cells was assessed according to their migration through a $12 \mu \mathrm{m}$ pore size polycarbonate filter (Neuro Probe, Inc., Gaithersburg, MD, USA) coated with Matrigel $(1 \mathrm{mg} / \mathrm{ml}$; Collaborative
Biomedical Products, Bedford, MA, USA), which was placed between the two compartments of an invasion chamber (Neuro Probe, Inc.). The lower compartment was filled with DMEM/Ham's-F12 medium containing $10 \%$ FCS. Single-cell suspensions $\left(1 \times 10^{5}\right.$ cells/well in a volume of $\left.100 \mu \mathrm{l}\right)$ of BON1 were added on top of the filter in the upper compartment. After $16 \mathrm{~h}$ of incubation, the filters were removed, and the cells were fixed and stained with toluidine blue. Cells on the upper side of the filter were removed with a cotton swab (except for control wells for the determination of total cell fraction). Filters were cut out, placed in $200 \mu \mathrm{l}$ of $1 \%$ SDS solution, and incubated for $60 \mathrm{~min}$ at $37^{\circ} \mathrm{C}$ to fully solubilize the toluidine blue stain. The absorbance of the dye was determined at $620 \mathrm{~nm}$. The fraction of invaded cells was calculated as follows: $\%$ invasion $=$ number of invaded cells/total cell number $\times 100$.
A

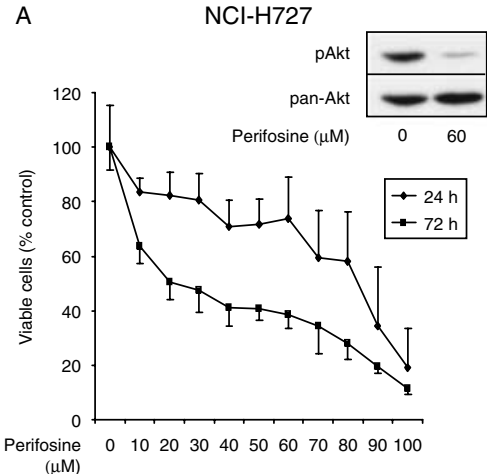

C

C BON1

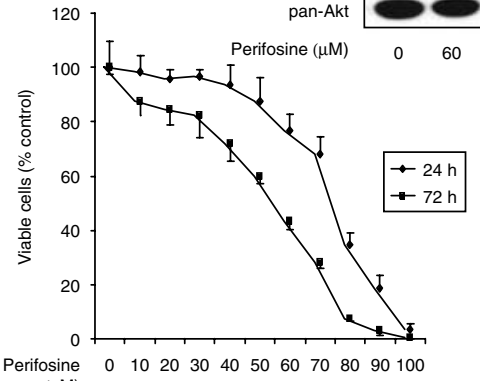

GOT1

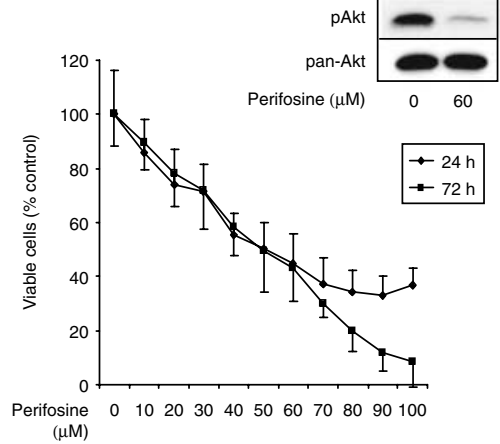

D

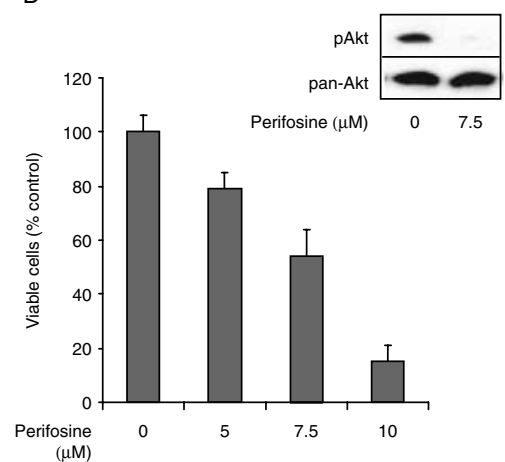

Figure 1 Perifosine-mediated inhibition of Akt phosphorylation and NET cell viability. NCl-H727 (A), GOT1 (B), and BON1 cells (C) were incubated with indicated concentrations of perifosine for 24 and $72 \mathrm{~h}$ in medium containing $10 \%$ FCS. Additionally, BON1 cells were incubated with indicated concentrations of perifosine for $72 \mathrm{~h}$ in medium containing $1 \%$ FCS (D). Cell viability was measured with Cell Titer 96 kit (Promega). Demonstrated are the mean values \pm s.D. of two independently performed experiments in sextuplicates $(n=12)$. All values were significantly different from control $(P<0.05)$ with the exception of values obtained by $24 \mathrm{~h}$ incubation of BON1 cells in medium containing $10 \%$ FCS and perifosine concentrations below $50 \mu \mathrm{M}$. NCl-H727 (A), GOT1 (B), and BON1 cells ( $C$ and $D)$ were incubated with indicated concentrations of perifosine for $2 \mathrm{~h}$ in medium containing $10 \% \mathrm{FCS}(\mathrm{A}, \mathrm{B}$ and $\mathrm{C})$ or $1 \%$ FCS (D). Protein expression levels of phosphorylated and total Akt were examined using western blot analysis. One representative blot out of three performed experiments is shown. 


\section{Protein extraction, immunoprecipitation, and western blotting}

Protein extraction and western blotting were performed as described previously in detail (Zitzmann et al. 2006). Primary antibodies used were pAkt (Ser473; \#4060), pan-Akt (\#2920), Akt1 (\#2967), Akt2 (\#2964), pERK1/2 (\#9101), ERK1/2 (\#9102), pJNK (\#9251), JNK (\#9252), pp70S6K (\#9234), p70S6K (\#9202), Bcl-XL (BCL2L1) (\#2762), pGSK3 $\alpha / \beta$ (\#9331), GSK3 $\beta$ (\#9315), and pMDM2 (\#3521; Cell Signaling, Danvers, MA, USA); BCL2 (610539; BD, Franklin Lakes, NJ, USA), Akt2 (sc-5270; Santa Cruz Biotechnology, Santa Cruz, CA, USA), Akt3 (MAB1463; R\&D Systems, Minneapolis, MN, USA), and $\beta$-actin (ab20272; Abcam).

\section{Quantification of DNA fragmentation and cell cycle analysis}

The rate of apoptotic cell death was quantified by determining DNA fragmentation according to Nicoletti et al. (1991). Briefly, cells were incubated for $24 \mathrm{~h}$ in a hypotonic buffer $(0.1 \%$ sodium citrate, $0.1 \%$ Triton $\mathrm{X}-100$, and $50 \mu \mathrm{g} / \mathrm{ml}$ propidium iodide) and analyzed by flow cytometry on a FACSCalibur analyzer (BD) using CellQuest Software (BD). Nuclei to the left of the $\mathrm{G}_{1}$-peak containing hypodiploid DNA were considered apoptotic.

\section{Statistical analysis}

Statistical analysis was performed using two-tailed Student's $t$-test. $P<0.05$ was considered statistically significant.

\section{Results}

\section{Perifosine decreases the viability of NET cells}

To determine the antitumor potential of Akt inhibition in NET disease, human pancreatic neuroendocrine BON1, bronchus carcinoid NCI-H727, and midgut carcinoid GOT1 tumor cells were incubated with increasing concentrations of the pan-Akt inhibitor perifosine for 24 and $72 \mathrm{~h}$ respectively. As shown in Fig. 1A, B and C, perifosine dose dependently decreased the viability of all examined NET cells. Significant effects were observed in all NET cell lines starting at concentrations as low as $10 \mu \mathrm{M}$ (NCI-H727 and GOT 1 cells after incubation for $24 \mathrm{~h}$, all NET cells after incubation for $72 \mathrm{~h}$ ) and peaked at the highest perifosine dose tested $(100 \mu \mathrm{M})$. Inhibition of neuroendocrine cell viability by perifosine was associated with decreased Akt phosphorylation as demonstrated by western blot (Fig. 1A, B and C). The inhibitory effect of perifosine was potently enhanced under low serum conditions (1\% FCS; Fig. 1D); therefore, serumreduced medium (1\% FCS) was used for further experiments.

\section{Perifosine induces apoptosis}

In order to examine the mechanism of inhibition of cell viability in NET cells by perifosine, BON1 cells were treated for $48 \mathrm{~h}$ with increasing concentrations of
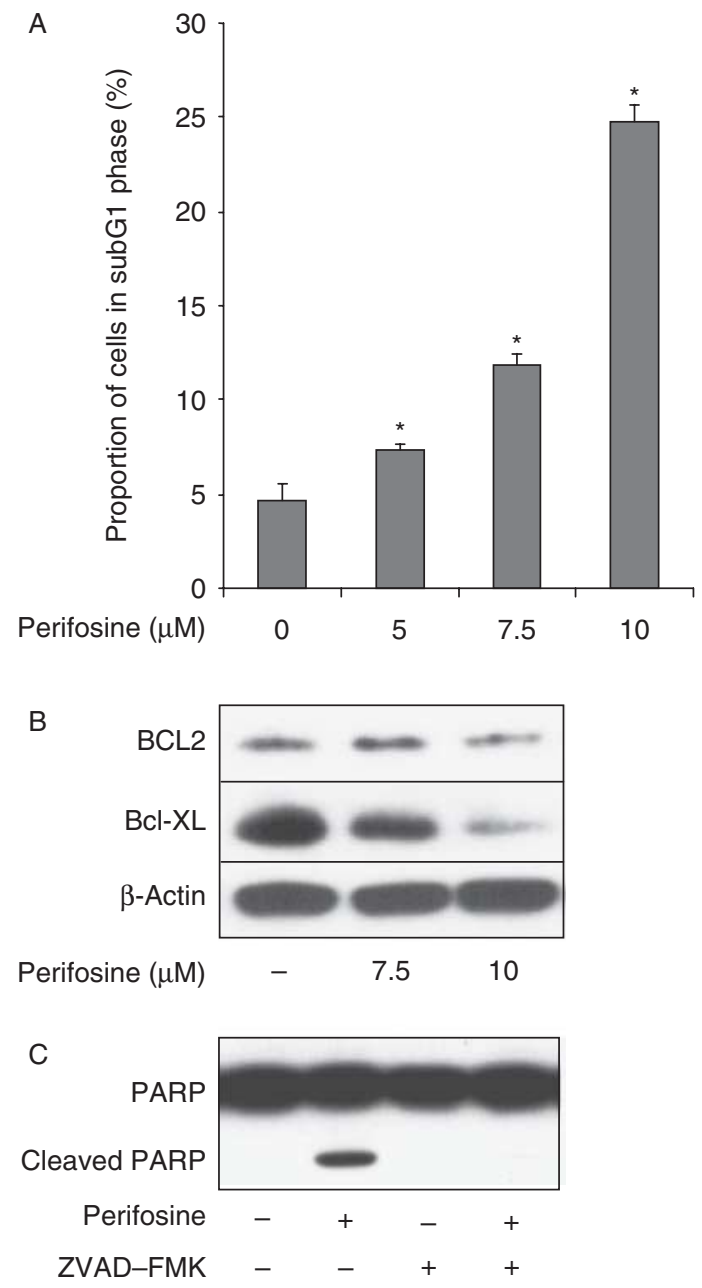

Figure 2 Perifosine-mediated induction of apoptosis. BON1 cells were treated with indicated concentrations of perifosine for $24 \mathrm{~h}$. (A) The proportion of cells in subG1 was examined by flow cytometry. Shown are the mean values \pm s.D. of one representative experiment in triplicates $(n=3)$ out of the three performed. (B) BON1 cells were treated with indicated concentrations of perifosine for $8 \mathrm{~h}$. The expression of BCL2 and Bcl-XL was evaluated by western blot analysis. (C) BON1 cells were treated with perifosine $(7.5 \mu \mathrm{M})$ alone or in combination with ZVADFMK $(40 \mu \mathrm{M})$. Total compared to cleaved PARP protein expression levels were examined using western blot analysis. For $\mathrm{B}$ and $\mathrm{C}$, one representative blot out of three performed experiments is shown, ${ }^{\star} P<0.05$ vs control. 
A
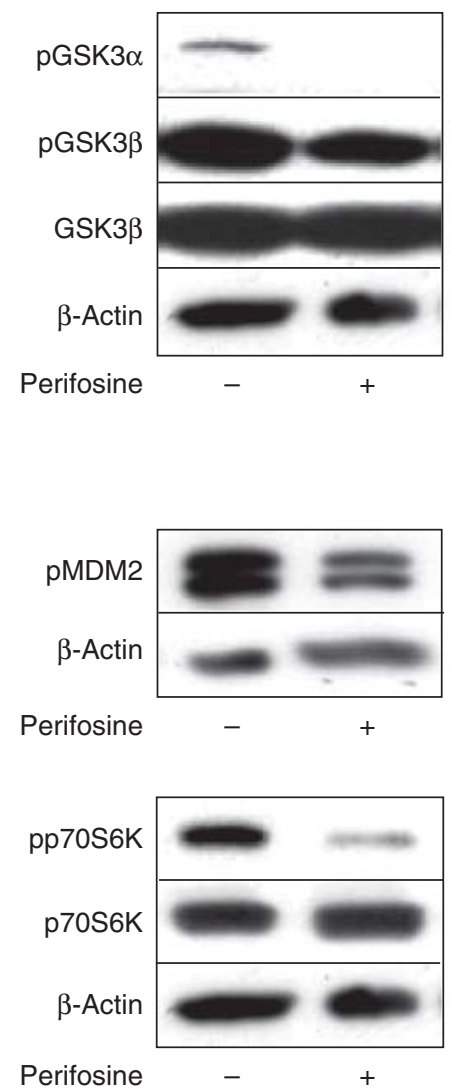

B
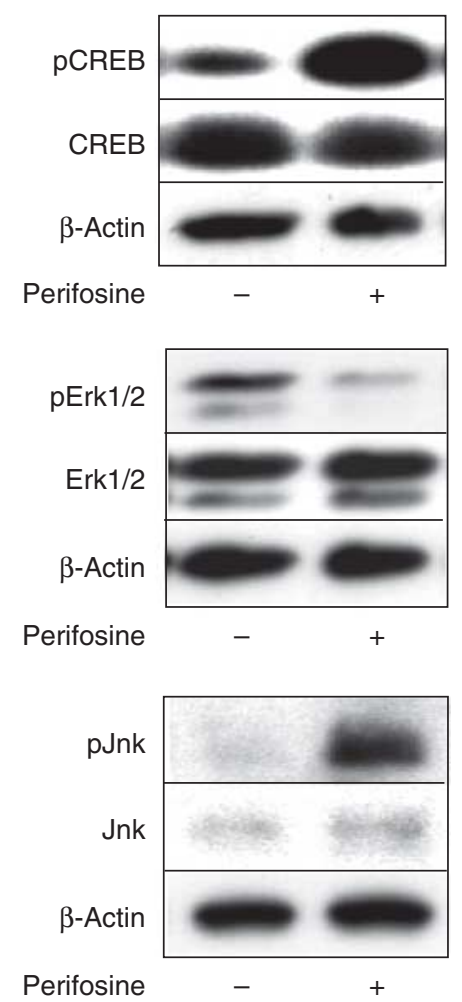

Figure 3 Perifosine-mediated inhibition of Akt downstream signaling. BON1 cells were treated with $7.5 \mu \mathrm{M}$ perifosine for $8 \mathrm{~h}$. Protein expression levels of pGSK3 $\alpha / \beta$, GSK3 $\alpha / \beta$, pMDM2, pp70S6K, p70S6K, pCREB, CREB, pERK1/2, ERK1/2, pJNK, Jnk, and $\beta$-actin loading control were examined using western blot analysis. For each protein, one representative blot out of three performed experiments is shown.

perifosine and cell cycle analysis was performed. Perifosine treatment did not significantly alter the cell cycle phase distribution of BON1 cells (data not shown) but dose dependently increased the number of subG1 events (Fig. 2A). Significant effects were observed at a concentration as low as $5 \mu \mathrm{M}$ and peaked at the highest concentration tested. Consistent to the data obtained by FACS analysis, perifosine decreased the expression of the anti-apoptotic proteins BCL2 and Bcl-XL (Fig. 2B). Specific induction of apoptosis by perifosine was confirmed by cleavage of PARP, which was abrogated by cotreatment with the pancaspase inhibitor ZVAD-FMK (40 $\mu$ M; Fig. 2C).

\section{Perifosine-mediated inhibition of Akt down- stream signaling}

Akt affects survival signaling through coordinated phosphorylation of multiple proteins of the apoptotic and cell cycle regulatory machinery. We thus examined the influence of perifosine on the phosphorylation status of several well-known Akt substrates. As measured by western blot, perifosine significantly decreased GSK3 $\alpha / \beta$, p70S6K, and

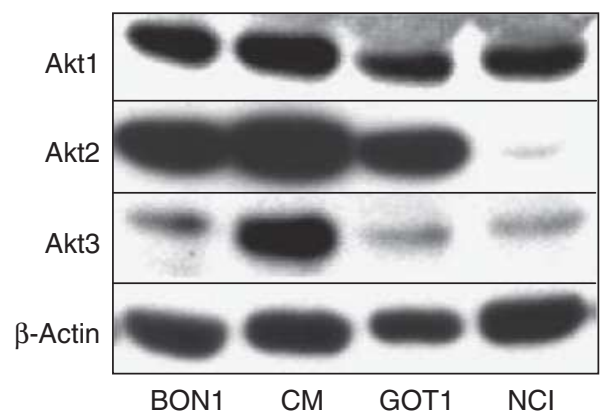

Figure 4 Expression patterns of Akt isoforms in neuroendocrine tumor cells. Basal expression levels of Akt1, Akt2, and Akt3 in human pancreatic BON1 and CM cells, midgut GOT1, and bronchus $\mathrm{NCl}-\mathrm{H} 727$ cells were detected by western blot analysis. 
MDM2 (Fig. 3A), while strongly inducing CREB phosphorylation (Fig. 3B). In order to identify whether CREB phosphorylation in response to perifosine is due to compensatory activation of MAPK survival signaling, we examined the phosphorylation status of ERK1/ 2 and JNK after $2 \mathrm{~h}$ of incubation with perifosine. While significantly decreasing the level of phosphorylated ERK1/2, perifosine treatment potently activated JNK signaling (Fig. 3B).

\section{Expression patterns of Akt isoforms in NET cells}

In order to elucidate the role of the different Akt isoforms in NET disease, we first examined the specificity of commercially obtained antibodies against Akt1 (Cell Signaling, Cat. \#2967), Akt2 (Santa Cruz, Cat. \#sc-5270 and Cell Signaling, Cat. \#2964), and Akt3 (R\&D, Cat. \#MAB1463). As determined by twodimensional gel electrophoresis, Akt1, Akt2, and Akt3 slightly differ in size (Supplementary Figure 1, see section on supplementary data given at the end of this article). Akt isoforms from whole cell lysates were separated by electrophoresis on a $8 \%$ SDS-polyacrylamide gel and transferred onto a polyvinylidene difluoride (PVDF) membrane, followed by western blot analysis with each Akt isoform-specific antibody. Anti-Akt1 and -Akt2 from Cell Signaling and antiAkt3 from R\&D showed no cross-reactivity (Supplementary Figure 2, see section on supplementary data given at the end of this article) between different Akt isoforms and were used for further experiments.

We next determined basal expression levels of Akt1, Akt2, and Akt3 in four NET cell lines of heterogeneous origin. The expression pattern of Akt1, Akt2, and Akt3 strongly varies between NET cells of bronchial (NCIH727), midgut (GOT1), and pancreatic (CM and BON1) origin (Fig. 4). All the four NET cell lines expressed significant amounts of Akt1. NCI-H727 cells expressed lower levels of Akt2 compared with the other NET cells, while highest Akt3 expression levels were detected in pancreatic CM cells (Fig. 4).

\section{Akt isoform-specific siRNA: effects on Akt downstream signaling}

To assess the specific role of each Akt isoform for downstream signaling within the classical PI(3)K-Akt survival pathway, we used siRNAs to specifically knockdown Akt1, Akt2, and Akt3. Akt1 and Akt2 siRNA selectively and potently reduced the expression of the corresponding Akt isoform (Fig. 5A and B). As Akt3 is barely detectable in BON1 and NCI-H727 cells, the specificity of Akt 3 siRNA was confirmed in
CM cells, which express relatively high basal levels of Akt3 (Fig. 5C).

We next examined the effect of Akt isoform-specific siRNA on the phosphorylation status of GSK $3 \alpha / \beta$, p70S6K, and MDM2 in human pancreatic BON1 cells by western blot analysis. Akt1 and Akt3 but not Akt 2 knockdown suppressed GSK3 $\alpha / \beta$, p70S6K, and MDM2 phosphorylation (Fig. 6A). Furthermore, Akt1 and Akt3 but not Akt2 knockdown potently decreased
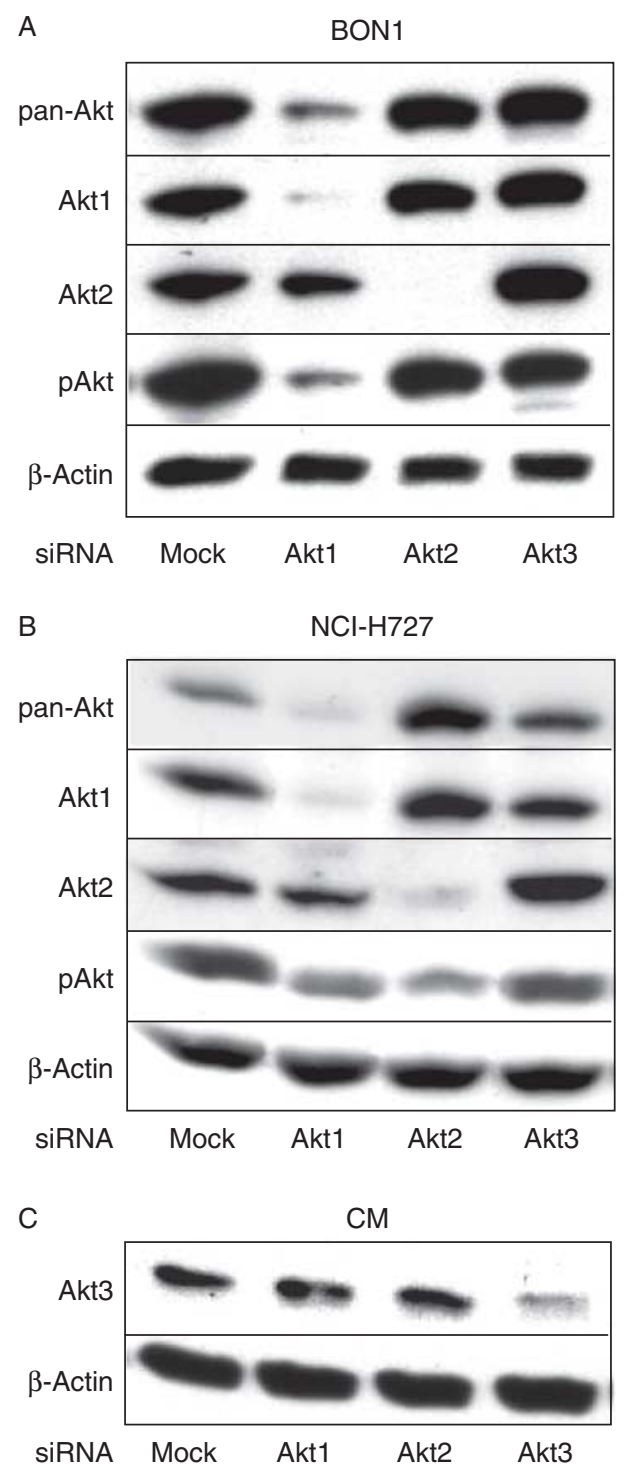

Figure 5 Akt isoform siRNA in neuroendocrine tumor cells. Human pancreatic BON1 (A), bronchus NCl-H727 (B), and pancreatic $C M(C)$ cells were transfected with nontargeted $B$-GAL siRNA or SiRNA against Akt1, Akt2, and Akt3. The effectiveness of the siRNAs was verified by western blot analysis of Akt1, Akt2, and Akt3 $48 \mathrm{~h}$ after transfection. For each protein, one representative blot out of three performed experiments is shown. 
the phosphorylation of ERK1/2 (Fig. 6B). To exclude the possibility that Akt1 and Akt3 compensate for each other to induce ERK1/2 signaling, BON1 cells were additionally double transfected with siRNA against Akt1 and Akt3. Significantly, the level of pERK1/2 was further decreased by simultaneous Akt1/Akt3 depletion (Fig. 6B).

Isoform-specific Akt siRNA: effects on cell viability, colony-forming capacity, and cell invasion in NET cells

To assess the effects of Akt1, Akt2, and Akt3 knockdown on NET cell viability, BON1 and NCIH727 cells were transfected with nontargeted $B-G A L$ siRNA or siRNA against Akt1, Akt2, or Akt3 and assayed for cell viability 72 and $144 \mathrm{~h}$ after transfection. In both the cell lines, downregulation of Akt1 and Akt3 significantly decreased cell viability (Fig. 7A and B). In contrast, transfection with Akt2-specific siRNA did not affect NCI-H727 cells but enhanced the viability of BON1 cells (Fig. 7A and B).

Similar to the observed effects on cell viability, the colony-forming capacity of Akt1 and Akt3 siRNAtransfected BON1 cells was substantially reduced while the transfection of Akt2 siRNA significantly increased the number of colonies 14 days after seeding (Fig. 7C).
Cell invasion of $A k t$ siRNA-treated BON1 cells was assessed with the use of a specific cell invasion assay. siRNA transfection with any Akt isoform-specific siRNA decreased BON1 cell invasion by $\sim 50 \%$ (Fig. 8A and B).

\section{Akt2 siRNA attenuates the antitumor effect of pan-Akt inhibition}

To compare the relative potency of Akt isoformspecific siRNA to pharmacological nonselective Akt inhibition, BON1 cells were transfected with nontargeted $B$-GAL siRNA, double transfected with siRNA against Akt1 and Akt3 or triple transfected with siRNA against Akt1, Akt2, and Akt3. The effectiveness of the double and triple transfection is shown in Fig. 9A. Consistent with the effects of Akt2 siRNA on cell viability in BON1 cells (Fig. 7A), double knockdown of Akt1 and Akt3 suppressed cell viability more effectively than triple knockdown of Akt1, Akt2, and Akt3 (Fig. 9B).

\section{Specific Akt3 siRNA induces apoptosis}

To elucidate the mechanisms underlying the loss of NET cell viability after Akt 1 and Akt3 deprivation, FACS analysis of BON1 cells transfected with nontargeted $B-G A L$ siRNA or siRNA against Akt1, $\mathrm{Akt} 2$, or Akt3 was performed. As assessed by flow

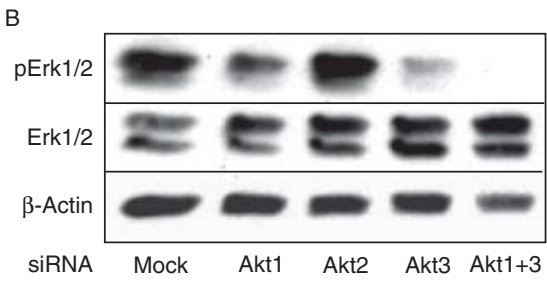

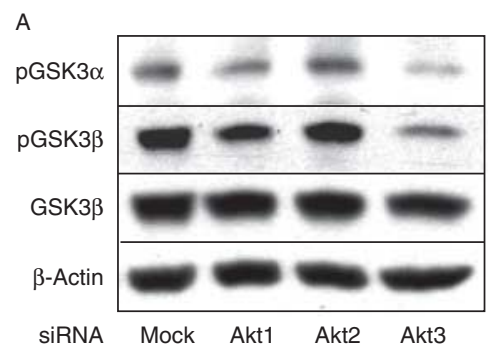
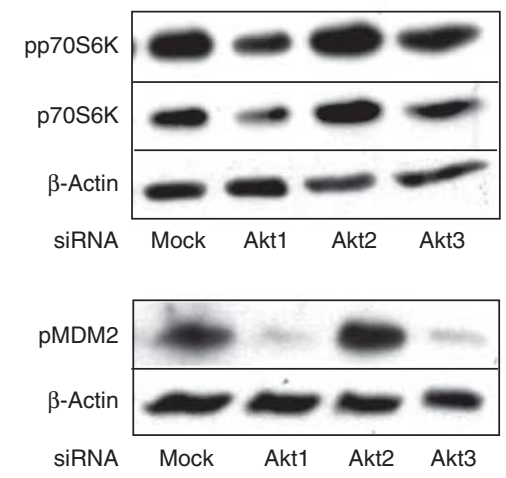

Figure 6 Effects of Akt siRNA on downstream signaling. Human pancreatic BON1 cells were mono-transfected with nontargeted $B$-GAL siRNA, siRNA against Akt1, Akt2, and Akt3 or double transfected with siRNA against Akt1 and Akt3. Forty-eight hours after transfection, the expression levels of pGSK3 $\alpha / \beta$, GSK3 $\alpha / \beta, \mathrm{MDM} 2$, pp70S6K, and p70S6K (A) as well as pERK1/2 and ERK1/2 (B) were evaluated by western blot analysis. For each protein, one representative blot out of three performed experiments is shown. 
cytometry, downregulation of Akt3 significantly increased the fraction of cells with subG1 DNA content (Fig. 10A). Specific induction of apoptosis was confirmed by decreased expression of BCL2 and Bcl-XL in Akt3 siRNA-treated BON1 cells (Fig. 10B).
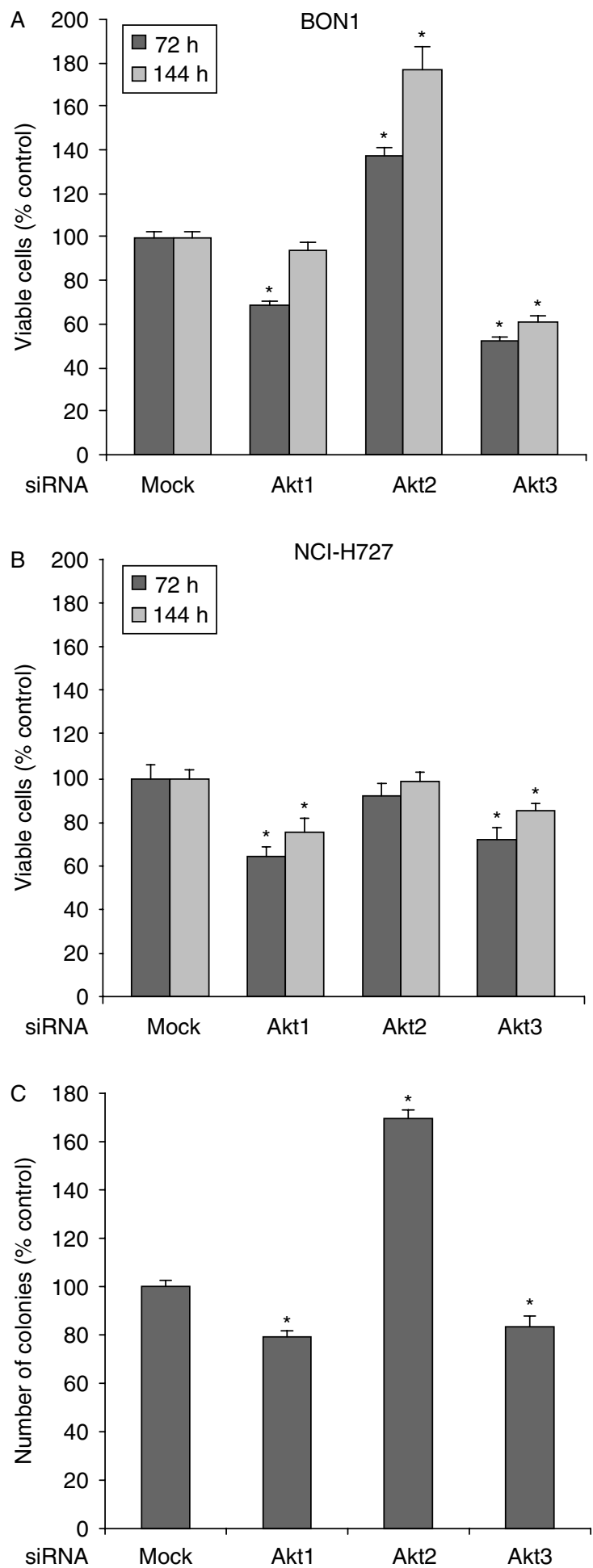

\section{Discussion}

The PI(3)K-Akt-mTOR signaling pathway is aberrantly active in most human cancers including NETs and offers an attractive therapeutic target. Two large placebo-controlled clinical phase III studies demonstrated efficacy of the mTOR inhibitor everolimus for the treatment of advanced pancreatic NETs and NETs of different origin suffering from carcinoid syndrome (Pavel et al. 2011, Yao et al. 2011). However, mTOR inhibition may lead to p70S6K-mediated feedback activation of PI3K/Akt signaling (O'Reilly et al. 2006). Direct Akt inhibition could override this compensatory mechanism, thus increasing the efficacy of pharmacological PI(3)K-Akt-mTOR pathway inhibition in NET disease.

In contrast to conventional Akt inhibitors, which target the ubiquitous ATP-binding pocket, perifosine binds the lipid-binding $\mathrm{PH}$ domain, thus interfering with the recruitment and activation of Akt more specifically. It is the first oral alkylphospholipid exerting promising growth inhibitory effects in a number of different tumor cell lines (Gills \& Dennis 2009). However, its activity on NET cells has not been investigated yet. In this study, we demonstrate that perifosine potently inhibits Akt phosphorylation and cell viability in three human NET cell lines of pancreatic, small intestine, and bronchus origin. Perifosine-mediated suppression of cell viability was associated with the induction of apoptosis, as confirmed by an increased fraction of cells with subG1 content and PARP cleavage. Consistent with the previous studies on other tumor entities, perifosine significantly reduced the phosphorylation levels of the known Akt downstream targets GSK3 $\alpha / \beta$, MDM2, and p70S6K. In addition, perifosine also inhibited RAFMEK-ERK1/2 signaling, a critical pathway for NET cell viability (Zitzmann et al. 2010). Recently, it has been shown that like Akt, ERK1/2 may also be upregulated in response to mTOR inhibition, thus potentially limiting the antitumor efficacy of mTOR inhibitors (Carracedo et al. 2008, Zitzmann et al. 2010, Svejda et al. 2011). Compared with mTOR inhibitors,

Figure 7 Effects of specific Akt isoform siRNA on NET cell viability and colony-forming capacity. Cell viability in siRNAtreated human pancreatic BON1 (A) and bronchus NCl-H727 (B) NET cells was measured using Cell Titer 96 kit (Promega) 72 and $144 \mathrm{~h}$ after transfection. Demonstrated are the mean values \pm s.D. of three independently performed experiments in sextuplicate $(n=18)$. The colony-forming capacity of BON1 cells was determined by enumeration of the formed colonies 14 days after plating $(\mathrm{C})$. Demonstrated are the mean values \pm S.D. of one representative experiment in triplicates $(n=3)$ out of three performed experiments. ${ }^{\star} P<0.05$ vs mock-transfected control. 
A
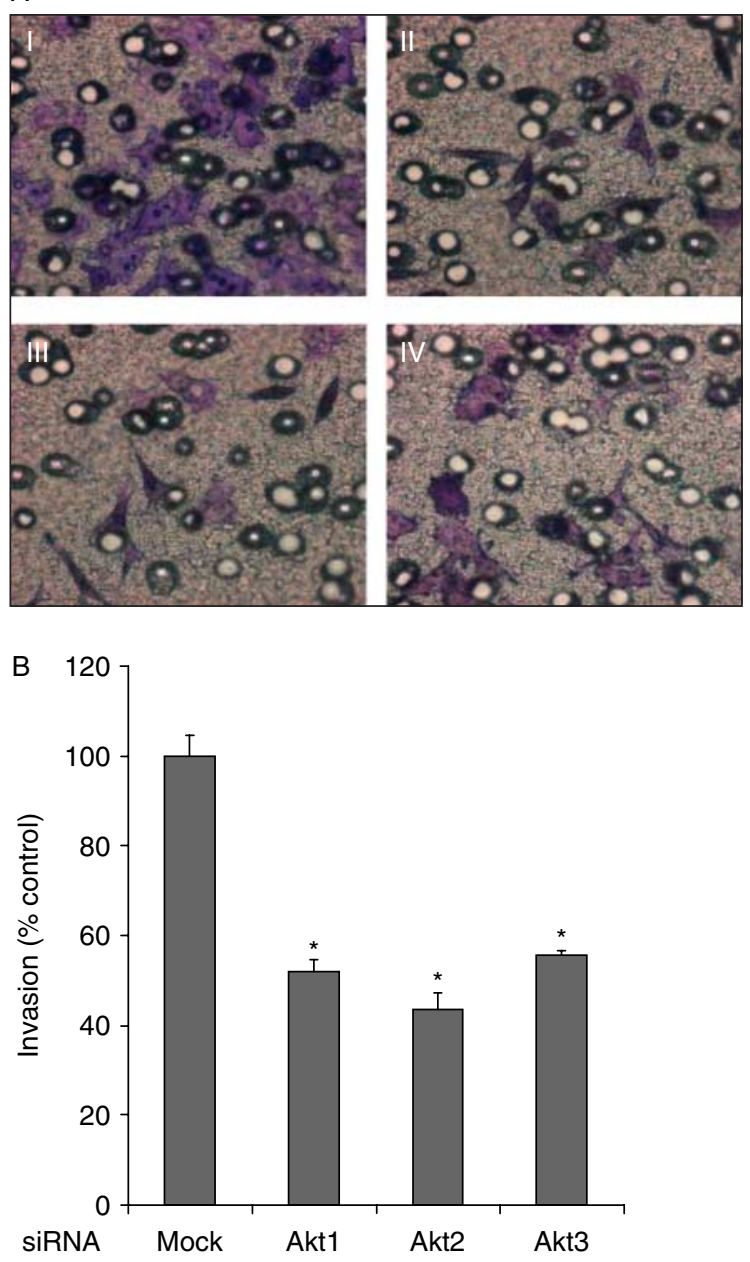

Figure 8 Effects of specific Akt isoform siRNA on neuroendocrine tumor cell invasion. BON1 cells were transfected with nontargeted $B-G A L$ (I) siRNA or siRNA against Akt1 (II), Akt2 (III) or Akt3 (IV). Forty-eight hours after transfection, the cells were loaded into invasion chambers and after $16 \mathrm{~h}$ of incubation, light microscopic pictures of the invaded cells were taken $(A)$ before their total numbers were evaluated as described in the Materials and methods section (B). Shown are the mean values \pm S.D. of three independently performed experiments in triplicates $(n=9)$. ${ }^{\star} P<0.05$ vs mock-transfected control.

direct Akt inhibition with perifosine appears to have a more broad inhibitory effect on the PI(3)K-AktmTOR pathway without compensatory activation of $\mathrm{PI}(3) \mathrm{K}$ and ERK1/2 signaling. On the other hand, perifosine induced CREB and JNK phosphorylation, suggesting a specific and nontoxic inhibitory effect on Akt and ERK signaling.

Several clinical phase I/II studies have explored the effects of perifosine alone and in different combination therapy approaches (Ernst et al. 2005, Argiris et al. 2006, Gills \& Dennis 2009, Ghobrial et al. 2010). Although high plasma concentrations up to $16.2 \mu \mathrm{M}$ have been reached, tumor response rates to perifosine as a single agent have been modest (Gills \& Dennis 2009). In contrast, preliminary reports of combination therapy with perifosine plus capecitabine in colon cancer and perifosine plus bortezomib and dexamethasone in multiple myeloma seem to be promising (Bendell et al. 2011, Richardson et al. 2011). However, to our knowledge, no clinical data on the effects of perifosine in NETs are yet available.

Akt exists in three different isoforms. All Akt isoforms have been shown to contribute to proliferation
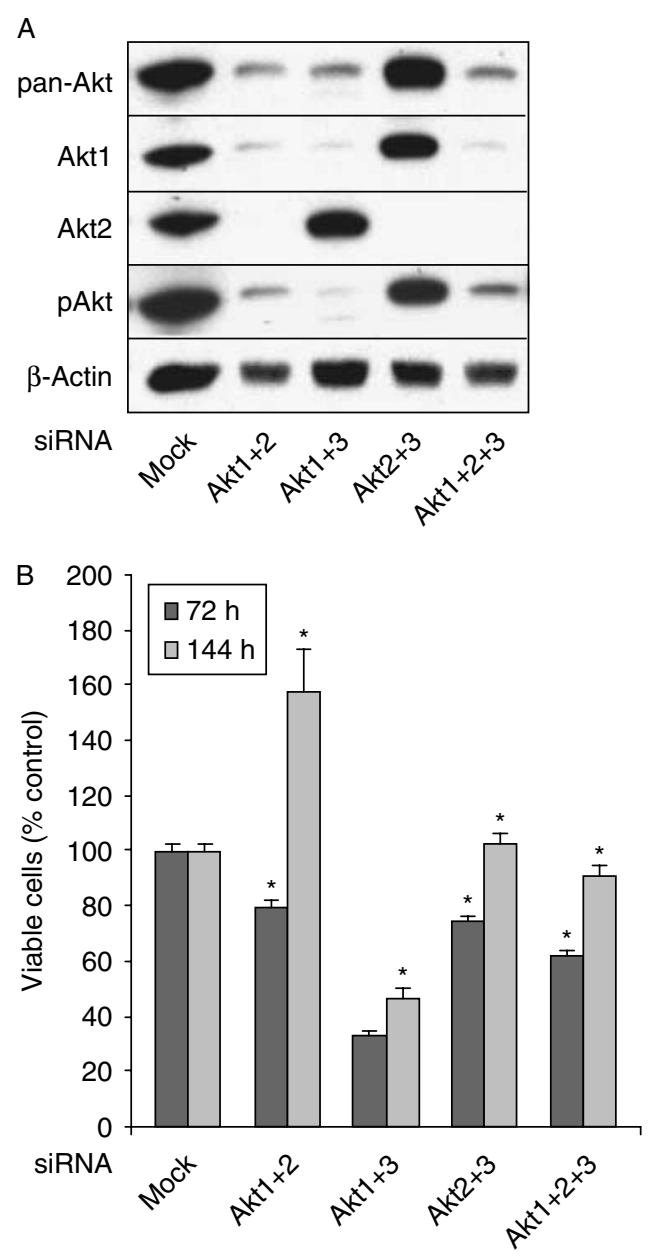

Figure 9 Akt2 siRNA attenuates the antitumor effect of pan-Akt inhibition in BON1 cells. ( $A$ and $B$ ) Human pancreatic BON1 cells were transfected with nontargeted $B-G A L$ siRNA, double transfected with siRNA against Akt1 and Akt3, or tripletransfected with siRNA against Akt1, Akt2, and Akt3. The effectiveness of the double and triple transfection was verified by western blot analysis $48 \mathrm{~h}$ after transfection $(A)$. One representative blot out of three performed experiments is shown. Cell viability was measured using Cell Titer 96 kit (Promega) 72 and $144 \mathrm{~h}$ after transfection (B). Demonstrated are the mean values \pm S.D. of three independently performed experiments in sextuplicate $(n=18) .{ }^{*} P<0.05$ vs untreated control. 

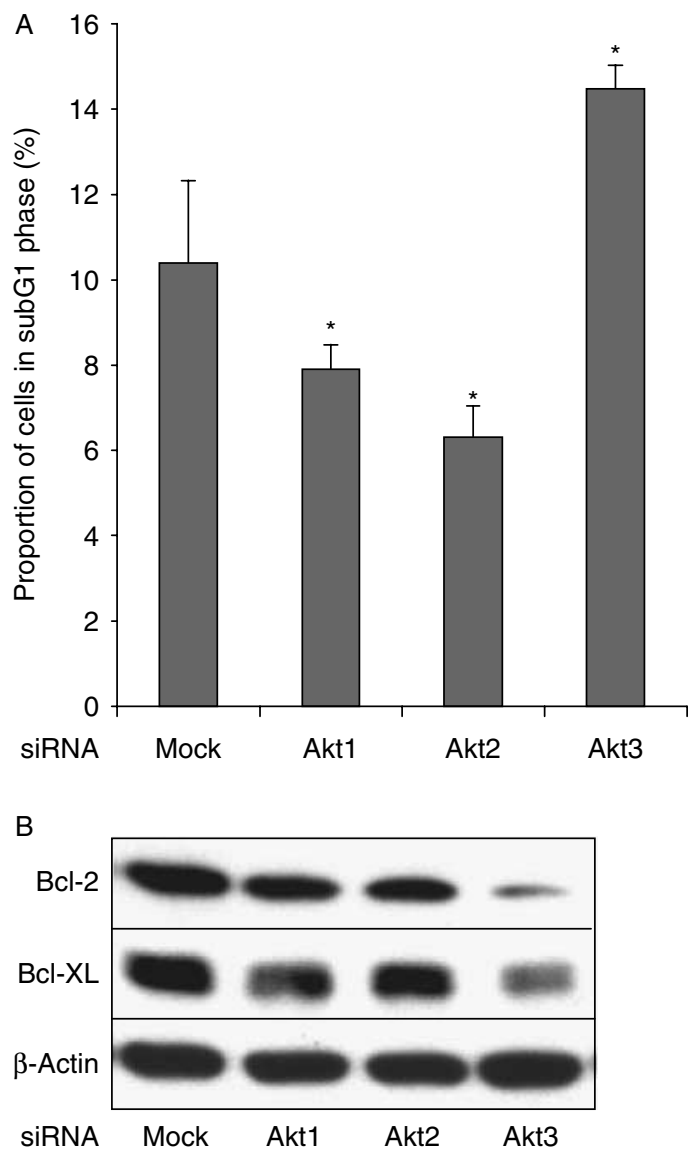

Figure 10 Specific Akt3 siRNA induces apoptosis in BON1 cells. BON1 cells were transfected with nontargeted $B-G A L$ siRNA or siRNA against Akt1, Akt2, or Akt3. Forty-eight hours after transfection, the proportion of cells in subG1 phase was examined by flow cytometry (A). Shown are the mean values \pm S.D. of one representative experiment in triplicates $(n=3)$ out of three experiments performed. ${ }^{*} P<0.05$ vs mock-transfected control. The expression of BCL2 and Bcl-XL was evaluated by western blot analysis (B). One representative blot out of three performed experiments is shown.

and cell survival, their relative importance seems to be cell-type specific (Koseoglu et al. 2007). In order to explore the mechanisms of Akt isoform-mediated regulation of NET cell activity, pancreatic BON1 and bronchus NCI-H727 cells were transfected with isoform-specific Akt siRNAs. Only downregulation of Akt1 and Akt3 decreased phosphorylation of the classical Akt downstream targets GSK3 $\alpha / \beta$, MDM2, and p70S6K and suppressed cell viability and colonyforming capacity, suggesting a particular role for these Akt isoforms in NET activity. Like perifosine, downregulation of Akt 1 and Akt3 significantly decreased ERK1/2 phosphorylation, indicating that these Akt isoforms positively control ERK1/2 activity. Furthermore, Akt3 ablation strongly induced apoptosis in
BON1 cells, indicating that this isoform is particularly relevant to NET cell survival.

To further evaluate the therapeutic potential of isoform-specific Akt inhibition in NET disease, double- and triple-transfection studies were performed. Significantly, the antitumor effect of simultaneous downregulation of Akt1 and Akt3 was much stronger than that caused by simultaneous downregulation of all Akt isoforms, demonstrating the potential advantage of selective Akt inhibition over pan-Akt inhibition in our NET cell model.

Together, our results demonstrate potent inhibitory effects of the pharmacological Akt inhibitor perifosine in NET cells. The lack of compensatory ERK or Akt activation as has been observed for mTOR inhibitors might offer therapeutic benefit. We could also demonstrate that particularly Akt1 and Akt3 seem to be important for NET cell viability while Akt2 may have antitumor activity. Thus, selective targeting of Akt1 and/or Akt3 might be even more effective in NET disease.

\section{Supplementary data}

This is linked to the online version of the paper at http://dx. doi.org/10.1530/ERC-12-0074.

\section{Declaration of interest}

The authors declare that there is no conflict of interest that could be perceived as prejudicing the impartiality of the research reported.

\section{Funding}

This study is in part supported by a grant from the German Federal Ministry of Education and Research (01EX1021B, Spitzencluster M4, Verbund Personalisierte Medizin: Teilprojekt NeoExNET (PM1)).

\section{References}

Argiris A, Cohen E, Karrison T, Esparaz B, Mauer A, Ansari R, Wong S, Lu Y, Pins M, Dancey J et al. 2006 A phase II trial of perifosine, an oral alkylphospholipid, in recurrent or metastatic head and neck cancer. Cancer Biology \& Therapy 5 766-770. (doi:10.4161/cbt.5.7.2874)

Bendell JC, Nemunaitis J, Vukelja SJ, Hagenstad C, Campos LT, Hermann RC, Sportelli P, Gardner L \& Richards DA 2011 Randomized placebo-controlled phase II trial of perifosine plus capecitabine as second- or third-line therapy in patients with metastatic colorectal cancer. Journal of Clinical Oncology 29 4394-4400.

(doi:10.1200/JCO.2011.36.1980) 
Carracedo A, Ma L, Teruya-Feldstein J, Rojo F, Salmena L, Alimonti A, Egia A, Sasaki AT, Thomas G, Kozma SC et al. 2008 Inhibition of mTORC1 leads to MAPK pathway activation through a PI3K-dependent feedback loop in human cancer. Journal of Clinical Investigation 118 3065-3074. (doi:10.1172/JCI34739)

Cho H, Mu J, Kim JK, Thorvaldsen JL, Chu Q, Crenshaw EB III, Kaestner KH, Bartolomei MS, Shulman GI \& Birnbaum MJ 2001 $a$ Insulin resistance and a diabetes mellitus-like syndrome in mice lacking the protein kinase Akt2 (PKB beta). Science 292 1728-1731. (doi:10.1126/ science.292.5522.1728)

Cho H, Thorvaldsen JL, Chu Q, Feng F \& Birnbaum MJ $2001 b$ Akt1/PKBalpha is required for normal growth but dispensable for maintenance of glucose homeostasis in mice. Journal of Biological Chemistry 276 38349-38352. (doi:10.1074/jbc.C100462200)

Dillon RL, Marcotte R, Hennessy BT, Woodgett JR, Mills GB \& Muller WJ 2009 Akt1 and Akt2 play distinct roles in the initiation and metastatic phases of mammary tumor progression. Cancer Research $695057-5064$. (doi:10.1158/0008-5472.CAN-08-4287)

Easton RM, Cho H, Roovers K, Shineman DW, Mizrahi M, Forman MS, Lee VM, Szabolcs M, de Jong R, Oltersdorf T et al. 2005 Role for Akt3/protein kinase Bgamma in attainment of normal brain size. Molecular and Cellular Biology 25 1869-1878. (doi:10.1128/MCB.25.5.18691878.2005)

Ernst DS, Eisenhauer E, Wainman N, Davis M, Lohmann R, Baetz T, Belanger K \& Smylie M 2005 Phase II study of perifosine in previously untreated patients with metastatic melanoma. Investigational New Drugs 23 569-575. (doi:10.1007/s10637-005-1157-4)

Ghobrial IM, Roccaro A, Hong F, Weller E, Rubin N, Leduc R, Rourke M, Chuma S, Sacco A, Jia X et al. 2010 Clinical and translational studies of a phase II trial of the novel oral Akt inhibitor perifosine in relapsed or relapsed/refractory Waldenstrom's macroglobulinemia. Clinical Cancer Research 16 1033-1041. (doi:10.1158/ 1078-0432.CCR-09-1837)

Gills JJ \& Dennis PA 2009 Perifosine: update on a novel Akt inhibitor. Current Oncology Reports 11 102-110. (doi:10. 1007/s11912-009-0016-4)

Hideshima T, Catley L, Yasui H, Ishitsuka K, Raje N, Mitsiades C, Podar K, Munshi NC, Chauhan D, Richardson PG et al. 2006 Perifosine, an oral bioactive novel alkylphospholipid, inhibits Akt and induces in vitro and in vivo cytotoxicity in human multiple myeloma cells. Blood 107 4053-4062. (doi:10.1182/blood-2005-083434)

Hutchinson JN, Jin J, Cardiff RD, Woodgett JR \& Muller WJ 2004 Activation of Akt-1 (PKB-alpha) can accelerate ErbB-2-mediated mammary tumorigenesis but suppresses tumor invasion. Cancer Research 64 3171-3178. (doi:10.1158/0008-5472.CAN-03-3465)

Kasajima A, Pavel M, Darb-Esfahani S, Noske A, Stenzinger A, Sasano H, Dietel M, Denkert C, Rocken C,
Wiedenmann B et al. 2011 mTOR expression and activity patterns in gastroenteropancreatic neuroendocrine tumours. Endocrine-Related Cancer 18 181-192. (doi:10.1677/ERC-10-0126)

Koseoglu S, Lu Z, Kumar C, Kirschmeier P \& Zou J 2007 AKT1, AKT2 and AKT3-dependent cell survival is cell line-specific and knockdown of all three isoforms selectively induces apoptosis in 20 human tumor cell lines. Cancer Biology \& Therapy 6 755-762. (doi:10.4161/cbt.6.5.3995)

Lee MW, Kim DS, Lee JH, Lee BS, Lee SH, Jung HL, Sung KW, Kim HT, Yoo KH \& Koo HH 2011 Roles of AKT1 and AKT2 in non-small cell lung cancer cell survival, growth, and migration. Cancer Science 102 1822-1828. (doi:10.1111/j.1349-7006.2011.02025.x)

Luo J, Manning BD \& Cantley LC 2003 Targeting the PI3K-Akt pathway in human cancer: rationale and promise. Cancer Cell 4 257-262. (doi:10.1016/S15356108(03)00248-4)

Mendoza MC \& Blenis J 2007 PHLPPing it off: phosphatases get in the Akt. Molecular Cell 25 798-800. (doi:10.1016/ j.molcel.2007.03.007)

Momota H, Nerio E \& Holland EC 2005 Perifosine inhibits multiple signaling pathways in glial progenitors and cooperates with temozolomide to arrest cell proliferation in gliomas in vivo. Cancer Research 65 7429-7435. (doi:10.1158/0008-5472.CAN-05-1042)

Mure H, Matsuzaki K, Kitazato KT, Mizobuchi Y, Kuwayama K, Kageji T \& Nagahiro S 2010 Akt2 and Akt3 play a pivotal role in malignant gliomas. NeuroOncology 12 221-232. (doi:10.1093/neuonc/nop026)

Nicoletti I, Migliorati G, Pagliacci MC, Grignani F \& Riccardi C 1991 A rapid and simple method for measuring thymocyte apoptosis by propidium iodide staining and flow cytometry. Journal of Immunological Methods 139 271-279. (doi:10.1016/0022-1759 (91)90198-O)

O'Reilly KE, Rojo F, She QB, Solit D, Mills GB, Smith D, Lane H, Hofmann F, Hicklin DJ, Ludwig DL et al. 2006 mTOR inhibition induces upstream receptor tyrosine kinase signaling and activates Akt. Cancer Research 66 1500-1508. (doi:10.1158/0008-5472.CAN-05-2925)

Pavel ME, Hainsworth JD, Baudin E, Peeters M, Horsch D, Winkler RE, Klimovsky J, Lebwohl D, Jehl V, Wolin EM et al. 2011 Everolimus plus octreotide long-acting repeatable for the treatment of advanced neuroendocrine tumours associated with carcinoid syndrome (RADIANT-2): a randomised, placebo-controlled, phase 3 study. Lancet 378 2005-2012. (doi:10.1016/S0140-6736(11)61742-X)

Rahmani M, Reese E, Dai Y, Bauer C, Payne SG, Dent P, Spiegel S \& Grant S 2005 Coadministration of histone deacetylase inhibitors and perifosine synergistically induces apoptosis in human leukemia cells through Akt and ERK1/2 inactivation and the generation of ceramide and reactive oxygen species. Cancer Research $\mathbf{6 5}$ 2422-2432. (doi:10.1158/0008-5472.CAN-04-2440) 
Richardson PG, Wolf J, Jakubowiak A, Zonder J, Lonial S, Irwin D, Densmore J, Krishnan A, Raje N, Bar M et al. 2011 Perifosine plus bortezomib and dexamethasone in patients with relapsed/refractory multiple myeloma previously treated with bortezomib: results of a multicenter phase I/II trial. Journal of Clinical Oncology 29 4243-4249. (doi:10.1200/JCO.2010.33.9788)

Saji M, Narahara K, McCarty SK, Vasko VV, La Perle KM, Porter K, Jarjoura D, Lu C, Cheng SY \& Ringel MD 2011 Akt1 deficiency delays tumor progression, vascular invasion, and distant metastasis in a murine model of thyroid cancer. Oncogene 30 4307-4315. (doi:10.1038/ onc.2011.136)

Sawyers CL 2006 Will kinase inhibitors have a dark side? New England Journal of Medicine 355 313-315. (doi:10.1056/NEJMcibr062354)

Shah T, Hochhauser D, Frow R, Quaglia A, Dhillon AP \& Caplin ME 2006 Epidermal growth factor receptor expression and activation in neuroendocrine tumours. Journal of Neuroendocrinology 18 355-360. (doi:10.1111/j.1365-2826.2006.01425.x)

Stahl JM, Sharma A, Cheung M, Zimmerman M, Cheng JQ, Bosenberg MW, Kester M, Sandirasegarane L \& Robertson GP 2004 Deregulated Akt3 activity promotes development of malignant melanoma. Cancer Research 64 7002-7010. (doi:10.1158/0008-5472.CAN04-1399)

Stambolic V \& Woodgett JR 2006 Functional distinctions of protein kinase B/Akt isoforms defined by their influence on cell migration. Trends in Cell Biology 16 461-466. (doi:10.1016/j.tcb.2006.07.001)

Svejda B, Kidd M, Kazberouk A, Lawrence B, Pfragner R \& Modlin IM 2011 Limitations in small intestinal neuroendocrine tumor therapy by mTor kinase inhibition reflect growth factor-mediated PI3K feedback loop activation via ERK1/2 and AKT. Cancer 117 4141-4154. (doi:10.1002/ cncr.26011)

Tschopp O, Yang ZZ, Brodbeck D, Dummler BA, Hemmings-Mieszczak M, Watanabe T, Michaelis T, Frahm J \& Hemmings BA 2005 Essential role of protein kinase B gamma (PKB gamma/Akt3) in postnatal brain development but not in glucose homeostasis. Development 132 2943-2954. (doi:10.1242/dev.01864)

Vink SR, Lagerwerf S, Mesman E, Schellens JH, Begg AC, van Blitterswijk WJ \& Verheij M 2006 Radiosensitization of squamous cell carcinoma by the alkylphospholipid perifosine in cell culture and xenografts. Clinical Cancer Research 12 1615-1622. (doi:10.1158/1078-0432.CCR05-2033)

Vlotides G, Sorensen AS, Kopp F, Zitzmann K, Cengic N, Brand S, Zachoval R \& Auernhammer CJ 2004 SOCS-1 and SOCS-3 inhibit IFN-alpha-induced expression of the antiviral proteins 2,5-OAS and MxA. Biochemical and Biophysical Research Communications 320 1007-1014. (doi:10.1016/j.bbrc.2004.06.051)

Wang L, Ignat A \& Axiotis CA 2002 Differential expression of the PTEN tumor suppressor protein in fetal and adult neuroendocrine tissues and tumors: progressive loss of PTEN expression in poorly differentiated neuroendocrine neoplasms. Applied Immunohistochemistry \& Molecular Morphology 10 139-146. (doi:10.1097/00022744200206000-00008)

Yao JC, Shah MH, Ito T, Bohas CL, Wolin EM, Van Cutsem E, Hobday TJ, Okusaka T, Capdevila J, de Vries EG et al. 2011 Everolimus for advanced pancreatic neuroendocrine tumors. New England Journal of Medicine 364 514-523. (doi:10.1056/NEJMoa1009290)

Zhang B, Gu F, She C, Guo H, Li W, Niu R, Fu L, Zhang N \& Ma Y 2009 Reduction of Akt2 inhibits migration and invasion of glioma cells. International Journal of Cancer 125 585-595. (doi:10.1002/ijc.24314)

Zitzmann K, Brand S, Baehs S, Goke B, Meinecke J, Spottl G, Meyer H \& Auernhammer CJ 2006 Novel interferonlambdas induce antiproliferative effects in neuroendocrine tumor cells. Biochemical and Biophysical Research Communications 344 1334-1341. (doi:10.1016/j.bbrc. 2006.04.043)

Zitzmann K, Ruden J, Brand S, Goke B, Lichtl J, Spottl G \& Auernhammer CJ 2010 Compensatory activation of Akt in response to $\mathrm{mTOR}$ and Raf inhibitors - a rationale for dual-targeted therapy approaches in neuroendocrine tumor disease. Cancer Letters 295 100-109. (doi:10.1016/j.canlet.2010.02.018)

Received in final form 3 April 2012 Accepted 12 April 2012 Made available online as an Accepted Preprint 12 April 2012 